\title{
Embryonic development of circadian clocks in the mammalian suprachiasmatic nuclei
}

\author{
Dominic Landgraf ${ }^{1}$, Christiane E. Koch ${ }^{2}$ and Henrik Oster ${ }^{2 *}$ \\ Center of Circadian Biology and Department of Psychiatry, University of California, San Diego, and Veterans Affairs San Diego Healthcare System, \\ San Diego, CA, USA \\ ${ }^{2}$ Chronophysiology Group, Medical Department I, University of Lübeck, Lübeck, Germany
}

Edited by:

Gonzalo Alvarez-Bolado, University

of Heidelberg, Germany

Reviewed by:

Manuel A. Pombal, University of

Vigo, Spain

Paul A. Gray, Washington

University, USA

*Correspondence:

Henrik Oster, Chronophysiology

Group, Medical Department I,

University of Lübeck, Ratzeburger

Allee 160, 23538 Lübeck, Germany

e-mail: henrik.oster@uksh.de
In most species, self-sustained molecular clocks regulate 24-h rhythms of behavior and physiology. In mammals, a circadian pacemaker residing in the hypothalamic suprachiasmatic nucleus (SCN) receives photic signals from the retina and synchronizes subordinate clocks in non-SCN tissues. The emergence of circadian rhythmicity during development has been extensively studied for many years. In mice, neuronal development in the presumptive SCN region of the embryonic hypothalamus occurs on days 12-15 of gestation. Intra-SCN circuits differentiate during the following days and retinal projections reach the SCN, and thus mediate photic entrainment, only after birth. In contrast the genetic components of the clock gene machinery are expressed much earlier and during midgestation SCN explants and isolated neurons are capable of generating molecular oscillations in culture. In vivo metabolic rhythms in the SCN, however, are observed not earlier than the 19th day of rat gestation, and rhythmic expression of clock genes is hardly detectable until after birth. Together these data indicate that cellular coupling and, thus, tissue-wide synchronization of single-cell rhythms, may only develop very late during embryogenesis. In this mini-review we describe the developmental origin of the SCN structure and summarize our current knowledge about the functional initiation and entrainment of the circadian pacemaker during embryonic development.

Keywords: suprachiasmatic nucleus, circadian clocks, embryonic and fetal development, entrainment, clock genes

\section{INTRODUCTION}

Endogenous circadian clocks facilitate the adaptation of behavior and physiology to the 24-h rhythm of day and night. In mammals, the circadian timing is organized by pacemaker cells in the hypothalamic suprachiasmatic nuclei (SCN). This SCN master clock is reset by photic time cues, or Zeitgebers, perceived through the retina and transmitted via the retino-hypothalamic tract (RHT). At the molecular level, the cellular clocks in the SCN and other tissues are built from self-sustained interlocked transcriptional-translational feedback loops of clock genes/proteins characterized by rhythmic transcription patterns. While clock function and rhythm generation have been extensively studied in adults, there is still no agreement on how circadian rhythms emerge during embryonic development.

\section{ANATOMICAL DEVELOPMENT OF THE SCN}

The ontogeny of the SCN has been extensively described in rodents (Figure 1), while only few data on primate SCN development are available (Weinert, 2005). The rat SCN is derived from the neuroepithelium of the preoptic recess of the third ventricle and becomes discernable as a discrete structure at embryonic day E17 (Altman and Bayer, 1978b). Neurogenesis in the rat mainly occurs between E12 and E18 with a maximum at E16 (Ifft, 1972; Altman and Bayer, 1978a). In mice neurogenesis begins earlier and is restricted to days E10-15, peaking at E12 (Shimada and Nakamura, 1973; Kabrita and Davis, 2008). In the hamster SCN, neurons are born even earlier at E9.5-13 (Davis et al., 1990; Antle et al., 2005). In squirrel monkeys, SCN neurons have been described at late gestational stages and, in humans, the SCN is discernable as a discrete structure around the 18th-30th week of pregnancy (Reppert and Schwartz, 1984; Reppert et al., 1988; Swaab et al., 1990).

The ontogeny of non-neuronal cell types within the SCN also follows temporal programs of formation (Botchkina and Morin, 1995; Antle et al., 2005). In the hamster SCN, radial glial cells start to develop at E8 and appear at high density in the SCN at E13. At post-natal day $0(\mathrm{PO})$, the density of these cells in the hamster SCN is drastically reduced and by P5 most of them are replaced by neurons. Hamster SCN astrocytes start to form at E15 and development continues at least until P21 (Botchkina and Morin, 1995). In the rat, astrocytes first appear at E20 and rapidly increase after birth, and radial glia cells are present at E17, which was the earliest stage investigated in this study (Munekawa et al., 2000), and begin to disappear at $\mathrm{P} 0$.

\section{ACTIVATION OF SCN MARKER GENE EXPRESSION}

The neuropeptides vasopressin (AVP) and vasoactive intestinal polypeptide (VIP) are strongly expressed in the SCN and contribute to its role as circadian pacemaker (Vosko et al., 2007; 


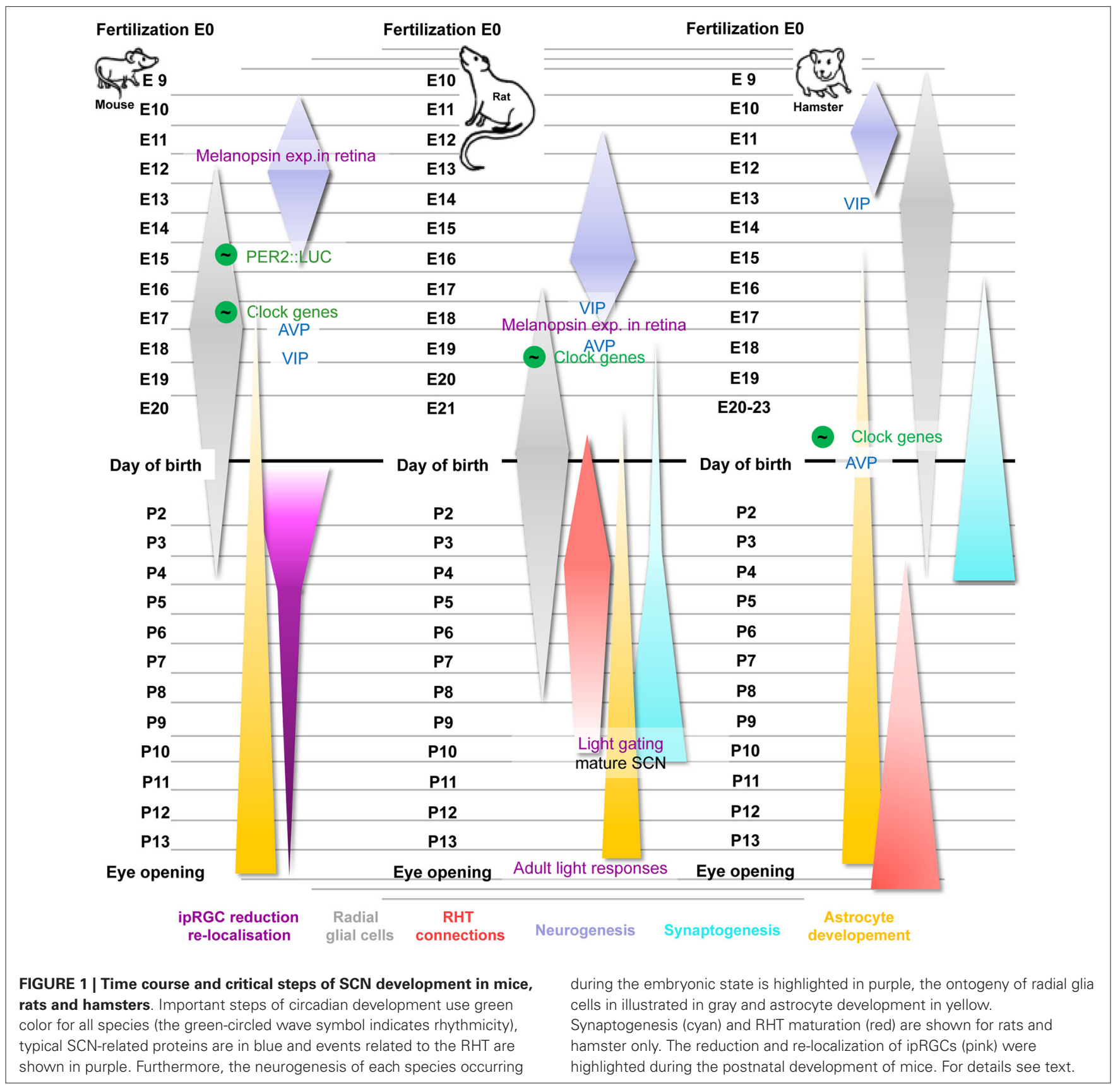

Kalsbeek et al., 2010). In the hamster SCN, AVP expressing cells first appear on the day of birth (Romero and Silver, 1990). In the mouse, AVP neurons first appear at E12 at the peak of neurogenesis (Okamura et al., 1983). However, AVP mRNA appears later at E17.5 of mouse development and AVP protein is only detectable at postnatal stages (VanDunk et al., 2011). From the 27th week of pregnancy, AVP is detectable in the human embryonic hypothalamus (Swaab et al., 1990). From then on, AVP levels constantly increase until 1-1.5 years after birth.

In the developing hamster SCN, VIP expressing neurons are detectable after completion of neurogenesis at E13-14 and VIP expression increases substantially until P10 (Romero and Silver,
1990; Botchkina and Morin, 1995). VIP mRNA first appears only after neurogenesis at E18.5 in the developing mouse SCN and VIP protein is detectable after birth (VanDunk et al., 2011). In contrast, in the rat SCN, VIP mRNA first appears directly after completion of neurogenesis at E18 and increases after birth until stage P20 (Ban et al., 1997). VIP protein in the rat SCN is first expressed no later than E20 (Laemle, 1988). However, earlier embryonic stages have not yet been investigated. The first VIP neurons in the human SCN are observed at $31^{\text {th }}$ week of pregnancy with increasing numbers until the age of 3 years. Spatial re-organization of VIP neurons, however, continues throughout puberty (Swaab et al., 1994). 
In mice, a combination of transcription factors shows distinct spatial and temporal patterns during prenatal and postnatal SCN development (VanDunk et al., 2011). The SCN anlage emerges from a specific region of the neuroepithelium expressing Six homeobox 3 and 6 (Six3, Six6), frizzled-5 (Fzd5), and transient retinal homeobox gene $(R x)$. Throughout embryonic development Six3, Lim homeodomain transcription factor 1 (Lhx1) and RARrelated orphan receptor alpha (Rora) expression remains restricted to the SCN region. Conditional deletion of Six3 at early stages prevents SCN development completely (VanDunk et al., 2011). In addition, Six6 is required for the normal development of the optic nerves and the SCN. Six6-null mice display abnormal entrainment behavior, due to the lack of functional optic nerves, but also show abnormal circadian rhythms under freerunning conditions, indicating the absence of a functional SCN. Indeed, immunohistochemical stainings for VIP and AVP confirmed the absence of a defined SCN structure in Six6-null mice (Clark et al., 2013). A selective deletion of SCN-enriched Lhxl in the developing anterior hypothalamus, including the developing SCN, leads to reduced SCN-enriched neuropeptides involved in circadian function and causes loss and death of neurons in the developing mouse SCN (Bedont et al., 2014). Furthermore, the loss of Lhxl during SCN development leads to reduced cellular synchrony in the SCN and results in disrupted circadian rhythms in adult mice (Bedont et al., 2014; Hatori et al., 2014).

\section{DEVELOPMENT OF CIRCADIAN PACEMAKER FUNCTION IN THE SCN}

At which embryonic stage endogenous SCN rhythms emerge, is still a matter of debate. Shortly before birth, glucose utilization in the embryonic SCN of squirrel monkeys shows diurnal rhythms (Reppert and Schwartz, 1983, 1984). Similarly, expression of the neuronal activity marker $c$-fos in the embryonic SCN of sheep at gestational day 135 shows diurnal fluctuations (Constandil et al., 1995). However, the mother animals used for these studies had functional circadian clocks and were housed in rhythmic light-dark (LD) conditions during the entire or at least during large parts of gestation. Thus, maternal or external timing cues driving diurnal rhythms observed in fetuses cannot be excluded and the existence of an endogenous fetal circadian clock cannot be concluded from these studies. Contrary, in rats it was shown that embryonic SCN rhythms emerge even in the absence of maternal clocks and under constant housing conditions. Glucose utilization and also neuronal firing of cultured embryonic rat SCNs at E22 exhibit circadian rhythms in vitro, suggesting that these oscillations are evoked by an endogenous clock (Shibata and Moore, 1987, 1988). In addition, the offspring of SCN-lesioned rat mothers displays circadian behavioral rhythms indicating that a functional circadian system develops in the absence of rhythmic maternal signals (Reppert and Schwartz, 1986). In humans, preterm infants of 29-35 weeks of age show circadian temperature rhythms under constant lighting and feeding conditions, which suggests the existence of a functional pacemaker during human gestation (Mirmiran and Kok, 1991).

Additional indirect evidence of functional embryonic SCN clocks comes from transplant studies. Implanting embryonic
SCN cells or grafts into the brain of SCN-lesioned adult hamsters restores free-running rhythms soon after transplantation (Silver et al., 1990; Kaufman and Menaker, 1993). Importantly, the outcome was independent of the age of the donor embryo suggesting that the SCN is already fully functional during midgestation.

In contrast, examination of clock gene or protein expression in fetal SCNs yields ambiguous results. In constant darkness, mRNA expression of Per1, but not Per2, is rhythmic at E17 in mice (Shimomura et al., 2001). At E18, PER1 and PER2 protein levels show circadian rhythms in the mouse embryonic SCN when mothers are kept in constant darkness, albeit with low baseline levels and moderate amplitude (Ansari et al., 2009). In rats kept under LD conditions, Per2 and Bmal1 mRNA expression is not rhythmic at E19, but on E21 (Houdek and Sumová, 2014). A different study has shown that Per1 and Per2 mRNA is already rhythmic in rat embryos at stage E20 (Ohta et al., 2002, 2003). Interestingly, although Per2 and Bmal1 expression is arrhythmic at E19 in the rat SCN, nuclear receptor subfamily 1, group D, member 1 (Nr1d1), c-fos, Avp, and Vip mRNAs already show significant circadian rhythms that are likely driven by maternal signals (Houdek and Sumová, 2014). Rhythmic Bmal1 and Per2 expression is seen in fetal SCNs of capuchin monkeys at late stages of gestation (Torres-Farfan et al., 2006). However, since the mother animals used in all these studies had a functional circadian clock and/or were kept in an LD cycle, an influence of rhythmic maternal signals on rhythmic clock gene expression in the embryonic SCN cannot be ruled out. Accordingly, other studies have shown that when pregnant rats are kept in constant darkness, Per1, Per2, and other clock gene mRNAs and proteins are not rhythmic in the embryonic SCN at E19/20 and rhythms only emerge around P1 (Sládek et al., 2004; Kováciková et al., 2006). However, cultured explants of PERIOD2::LUCIFERASE (PER2::LUC) mice, which carry the firefly luciferase gene in the wild-type circadian clock gene Per2 as a reporter for circadian rhythms (Yoo et al., 2004), revealed the capability of early embryonic SCNs of stage E15 to express self-sustained circadian rhythms in vitro. With advancing age of the embryos, the rhythms became gradually stronger (Wreschnig et al., 2014). Whether the observed rhythms reflect circadian oscillations that were already present in vivo or whether rhythms were induced by the tissue preparation procedure could, however, not be clarified.

\section{ENTRAINMENT OF THE FETAL SCN}

A hallmark of circadian clocks is their ability to entrain to external Zeitgebers. Circadian rhythms in the embryonic SCN of different species, including humans, strongly react to different signals including light, melatonin, food, and dopamine.

Depending on the lighting conditions, rat embryos show different phasing in glucose utilization rhythms (Reppert and Schwartz, 1983). When pregnant rats are housed under normal or inverted LD cycles, the embryonic SCN entrains to the external conditions. SCNs of squirrel monkey embryos from mothers housed in different LD cycles stay in phase with the maternal rhythm (Reppert and Schwartz, 1984). However, since synaptic connections from the retina to the SCN are only formed 
after birth (see below) these studies suggest an indirect entrainment of embryonic SCN clocks by light, probably via signals derived from the mother and passed on through the placental barrier. One candidate for a maternal signal, which entrains the embryonic clock, is melatonin released by the pineal gland (Wurtman et al., 1964) as daily melatonin injections can reset embryonic rhythms in pregnant SCN-lesioned hamsters (Davis and Mannion, 1988). A single injection of melatonin one day before birth is sufficient to shift the phase of the offspring (Viswanathan and Davis, 1997). In pregnant pinealectomized rats arrhythmicized by constant light melatonin injections influence the phase of $A v p$ and $c$-fos expression in the offspring (Houdek et al., 2014). Melatonin effects on fetal SCNs are mediated through locally expressed melatonin receptors. In capuchin monkey fetuses, melatonin 1 receptor (MT1) is strongly expressed in the SCN and suppression of maternal melatonin changes oscillating expression patterns of Bmal1, Per2 and MT1 (TorresFarfan et al., 2006). At around midgestation, the human embryonic SCN also expresses melatonin binding sites (Reppert et al., 1988).

Periodic feeding of pregnant SCN-lesioned rats synchronizes drinking behavior in the offspring, suggesting that feeding can entrain the SCN clock of fetuses during embryogenesis (Weaver and Reppert, 1989). Even in pregnant rats housed in LD with an intact circadian clock, time-restricted feeding shifts Perl expression in the fetal SCN by several hours when food is restricted to a 4 -h period in the inactive phase of the animals (Ohta et al., 2008). In contrast, $c$-fos and Avp expression patterns are not affected. However, when the circadian clocks of the rat mothers are disrupted by constant light exposure, restricted feeding resets $c$-fos and Avp expression of the newborns suggesting that light may be a stronger Zeitgeber for the fetal SCN than food-related signals (Nováková et al., 2010).

Dopamine is a potent regulator of the molecular circadian clock machinery (Yujnovsky et al., 2006). Timed treatment with SKF 38393, a dopamine receptor agonist, shifts the activity phase of the offspring from SCN-lesioned hamster mothers (Viswanathan et al., 1994; Viswanathan and Davis, 1997). Interestingly, melatonin injections have similar effects, but lead to opposite shifts in offspring activity. Dopamine and lightinduced glutamatergic signaling converge on shared intracellular kinase pathways (Schurov et al., 2002; Govindarajan et al., 2006; Colwell, 2011). However, light and the melatonin phase response curves are about $12 \mathrm{~h}$ out of phase (Lewy et al., 1998), which may explain the opposite directional effects on offspring activity.

\section{EMBRYONIC AND POSTNATAL DEVELOPMENT OF SCN INPUT PATHWAYS}

After birth, light becomes the most important Zeitgeber to entrain circadian rhythms and also influences the maturation of the SCN itself. Irradiance information is received by melanopsin-expressing intrinsically photosensitive retinal ganglion cells (ipRGCs). ipRGCs directly sense light, but also integrate input from rod and cone photoreceptors and signal via the RHT to the SCN. Melanopsin, the photopigment of the ipRGCs, is detectable in the retina of prenatal rodents-mice
E11.5 (Tarttelin et al., 2003), rats E18 (Fahrenkrug et al., 2004)_ and ipRGCs become light responsive directly after gestation (Sekaran et al., 2005; Tu et al., 2005). However, at this time ipRGCs are randomly distributed throughout the ganglion cell layer and the inner nuclear layer of the mouse retina ( $\mathrm{Tu}$ et al., 2005). Between birth and adulthood, re-organization as well as reduction of about $65 \%$ of ipRGCs occurs. During maturation ipRGCs separate into distinct regions of the inner plexiform layer. At P4, most of them are located in this region, but further separation occurs during the following days. This re-organization is accompanied by a profound loss of melanopsin-positive cells (Sekaran et al., 2005; Tu et al., 2005) that is associated with a 10fold increase in photic sensitivity at P4-6. This increase is partially, but not solely, induced by a gradual increase in retinal melanopsin expression (Tu et al., 2005). Almost simultaneously, the first circadian rhythm of melanopsin gene (OPN4) expression is observed around P5 (González-Menéndez et al., 2009) indicating a further maturation of the ipRGCs.

Paralleling ipRGC development, the RHT that is principally functional directly after birth at P0 in mice (Lupi et al., 2006) and P1 in rats (Leard et al., 1994), maturates during the first 1-2 weeks after birth to reach full functionality in rats (Takahashi and Deguchi, 1983; Duncan et al., 1986). Whereas the development of the RHT of hamsters starts at P4 and reaches the adult pattern by P15, its development in rats initiates prenatally at E21-22. First connections to the ventral part of the rat SCN appear at $\mathrm{P} 1$, reaching maximal density at $\mathrm{P} 4$ and prune back to the adult pattern by P10. At that stage, the first gating of light induced $c$ Fos production is detectable in the SCN of rat pups (Bendová et al., 2004). While the maturation of the light signaling cascade is mostly finished by P10 in rats (Speh and Moore, 1993), it was shown in mice that the adult-like light response is detectable not until around P14 when the eye opening occurs (Muñoz Llamosas et al., 2000), indicating that opening the eyes and removing the light dampening cover over it enables the rodent to fully respond to the environmental light.

Whether changes in pre- or postnatal lighting conditions may interfere with the functional development of ipRGCs, the RHT or the SCN itself is not known. However, light input during postnatal phase may affect neuropeptide expression in the SCN and the circadian system. CBA/J mice, which show increased photosensitivity compared with $\mathrm{C} 57 \mathrm{Bl} / 6$ mice, display elevated VIP and AVP levels in the SCN (Ruggiero et al., 2010) that are paradoxically associated with attenuated phase shifting behaviors (Yoshimura et al., 1994; Ruggiero et al., 2009). Additionally, constant postnatal light or darkness conditions affect the stability of circadian behavioral rhythms in mice (Canal-Corretger et al., 2000, 2001), possibly due to changes in astrocyte development in the SCN (Canal et al., 2009). Darkness exposure leads to more and larger astrocytes whereas constant light reduces SCN astrocyte numbers associated with an increased stability of circadian rhythms and overall increased running-wheel activity (Canal et al., 2009).

\section{CONCLUSION}

While the structural development of the SCN is relatively well understood, the question whether endogenous circadian 
rhythmicity in the SCN develops before birth is still matter of debate and studies based on SCN output or clock gene expression in the SCN provide different results. Species-specific traits make it difficult to draw a generally valid conclusion and the majority of studies investigating the existence of embryonic clocks are carried out in rhythmic environments and/or with pregnant females, which have a functional circadian clock. Consequently, environmental or maternal rhythmic signals driving diurnal rhythms in the embryonic SCN cannot be excluded, and the presence of an endogenous, self-sustained fetal SCN clock cannot be demonstrated. Studying pup development in arrhythmic mothers continually housed in constant environments during pregnancy may be a feasible approach to this problem. It was shown that behavioral rhythms of pups born under such conditions are not synchronized to each other. This complicates the investigation of rhythmic gene expression in embryonic SCNs because most techniques applied to measure gene activity only allow investigating one time point per animal. An alternative approach using animals carrying circadian-controlled reporters for continuous recording of transcriptional/translational activity from one specimen was conducted. However, to clarify whether clock gene oscillations of in vitro SCN explants reflect rhythms that were already present in vivo or that were rather initiated by the tissue culture procedure, SCN tissues may be collected and cultured at different daytimes. If explant phasing was determined by in vivo rhythms, phasing for all groups should be roughly the same and should be independent of the preparation time. In combination with improved in vivo imaging techniques this may finally facilitate the determination of the emergence of SCN and peripheral tissue clock function during ontogeny and allow a clear distinction between maternal and embryo-derived rhythms.

\section{REFERENCES}

Altman, J., and Bayer, S. A. (1978a). Development of the diencephalon in the rat. I. Autoradiographic study of the time of origin and settling patterns of neurons of the hypothalamus. J. Comp. Neurol. 182, 945-971. doi: 10.1002/cne.901820511

Altman, J., and Bayer, S. A. (1978b). Development of the diencephalon in the rat. II. Correlation of the embryonic development of the hypothalamus with the time of origin of its neurons. J. Comp. Neurol. 182, 973-993. doi: 10.1002/cne. 901820512

Ansari, N., Agathagelidis, M., Lee, C., Korf, H. W., and von Gall, C. (2009). Differential maturation of circadian rhythms in clock gene proteins in the suprachiasmatic nucleus and the pars tuberalis during mouse ontogeny. Eur. J. Neurosci. 29, 477-489. doi: 10.1111/j.1460-9568.2008.06605.x

Antle, M. C., LeSauter, J., and Silver, R. (2005). Neurogenesis and ontogeny of specific cell phenotypes within the hamster suprachiasmatic nucleus. Brain Res. Dev. Brain Res. 157, 8-18. doi: 10.1016/j.devbrainres.2005.02.017

Ban, Y., Shigeyoshi, Y., and Okamura, H. (1997). Development of vasoactive intestinal peptide mRNA rhythm in the rat suprachiasmatic nucleus. J. Neurosci. 17, 3920-3931.

Bedont, J. L., LeGates, T. A., Slat, E. A., Byerly, M. S., Wang, H., Hu, J., et al. (2014). Lhxl controls terminal differentiation and circadian function of the suprachiasmatic nucleus. Cell Rep. 7, 609-622. doi: 10.1016/j.celrep.2014.03.060

Bendová, Z., Sumová, A., and Illnerová, H. (2004). Development of circadian rhythmicity and photoperiodic response in subdivisions of the rat suprachiasmatic nucleus. Brain Res. Dev. Brain Res. 148, 105-112. doi: 10.1016/j. devbrainres.2003.10.007

Botchkina, G. I., and Morin, L. P. (1995). Ontogeny of radial glia, astrocytes and vasoactive intestinal peptide immunoreactive neurons in hamster suprachiasmatic nucleus. Brain Res. Dev. Brain Res. 86, 48-56. doi: 10.1016/01653806(95)00017-8
Canal, M. M., Mohammed, N. M., and Rodríguez, J. J. (2009). Early programming of astrocyte organization in the mouse suprachiasmatic nuclei by light. Chronobiol. Int. 26, 1545-1558. doi: 10.3109/07420520903398542

Canal-Corretger, M. M., Cambras, T., Vilaplana, J., and Díez-Noguera, A. (2000). Bright light during lactation alters the functioning of the circadian system of adult rats. Am. J. Physiol. Regul. Integr. Comp. Physiol. 278, R201-R208.

Canal-Corretger, M. M., Vilaplana, J., Cambras, T., and Díez-Noguera, A. (2001). Functioning of the rat circadian system is modified by light applied in critical postnatal days. Am. J. Physiol. Regul. Integr. Comp. Physiol. 280, R1023-R1030.

Clark, D. D., Gorman, M. R., Hatori, M., Meadows, J. D., Panda, S., and Mellon, P. L. (2013). Aberrant development of the suprachiasmatic nucleus and circadian rhythms in mice lacking the homeodomain protein Six6. J. Biol. Rhythms 28, 15-25. doi: 10.1177/0748730412468084

Colwell, C. S. (2011). Linking neural activity and molecular oscillations in the SCN. Nat. Rev. Neurosci. 12, 553-569. doi: 10.1038/nrn3086

Constandil, L., Parraguez, V. H., Torrealba, F., Valenzuela, G., and Serón-Ferré, M. (1995). Day-night changes in c-fos expression in the fetal sheep suprachiasmatic nucleus at late gestation. Reprod. Fertil. Dev. 7, 411-413. doi: 10.1071/rd99 50411

Davis, F. C., Boada, R., and Ledeaux, J. (1990). Neurogenesis of the hamster suprachiasmatic nucleus. Brain Res. 519, 192-199. doi: 10.1016/00068993(90)90077-o

Davis, F. C., and Mannion, J. (1988). Entrainment of hamster pup circadian rhythms by prenatal melatonin injections to the mother. Am. J. Physiol. 255, R439-R448.

Duncan, M. J., Banister, M. J., and Reppert, S. M. (1986). Developmental appearance of light-dark entrainment in the rat. Brain Res. 369, 326-330. doi: 10. 1016/0006-8993(86)90544-5

Fahrenkrug, J., Nielsen, H. S., and Hannibal, J. (2004). Expression of melanopsin during development of the rat retina. Neuroreport 15, 781-784. doi: 10. 1097/00001756-200404090-00008

González-Menéndez, I., Contreras, F., Cernuda-Cernuda, R., and GarcíaFernández, J. M. (2009). Daily rhythm of melanopsin-expressing cells in the mouse retina. Front. Cell. Neurosci. 3:3. doi: 10.3389/neuro.03.003.2009

Govindarajan, A., Kelleher, R. J., and Tonegawa, S. (2006). A clustered plasticity model of long-term memory engrams. Nat. Rev. Neurosci. 7, 575-583. doi: 10. 1038/nrn1937

Hatori, M., Gill, S., Mure, L. S., Goulding, M., O’Leary, D. D., and Panda, S. (2014). Lhx1 maintains synchrony among circadian oscillator neurons of the SCN. Elife 3:e03357. doi: 10.7554/eLife.03357

Houdek, P., Polidarová, L., Nováková, M., Matějů, K., Kubík, S., and Sumová, A. (2014). Melatonin administered during the fetal stage affects circadian clock in the suprachiasmatic nucleus but not in the liver. Dev. Neurobiol. doi: 10. 1002/dneu.22213. [Epub ahead of print].

Houdek, P., and Sumová, A. (2014). In vivo initiation of clock gene expression rhythmicity in fetal rat suprachiasmatic nuclei. PLoS One 9:e107360. doi: 10. 1371/journal.pone.0107360

Ifft, J. D. (1972). An autoradiographic study of the time of final division of neurons in rat hypothalamic nuclei. J. Comp. Neurol. 144, 193-204. doi: 10.1002/cne. 901440204

Kabrita, C. S., and Davis, F. C. (2008). Development of the mouse suprachiasmatic nucleus: determination of time of cell origin and spatial arrangements within the nucleus. Brain Res. 1195, 20-27. doi: 10.1016/j.brainres.2007.12.020

Kalsbeek, A., Fliers, E., Hofman, M. A., Swaab, D. F., and Buijs, R. M. (2010). Vasopressin and the output of the hypothalamic biological clock. J. Neuroendocrinol. 22, 362-372. doi: 10.1111/j.1365-2826.2010.01956.x

Kaufman, C. M., and Menaker, M. (1993). Effect of transplanting suprachiasmatic nuclei from donors of different ages into completely SCN lesioned hamsters. $J$. Neural Transplant. Plast. 4, 257-265. doi: 10.1155/np.1993.257

Kováciková, Z., Sládek, M., Bendová, Z., Illnerová, H., and Sumová, A. (2006). Expression of clock and clock-driven genes in the rat suprachiasmatic nucleus during late fetal and early postnatal development. J. Biol. Rhythms 21, 140-148. doi: $10.1177 / 0748730405285876$

Laemle, L. K. (1988). Vasoactive intestinal polypeptide (VIP)-like immunoreactivity in the suprachiasmatic nucleus of the perinatal rat. Brain Res. 469, 308-312. doi: 10.1016/0165-3806(88)90193-9

Leard, L. E., Macdonald, E. S., Heller, H. C., and Kilduff, T. S. (1994). Ontogeny of photic-induced c-fos mRNA expression in rat suprachiasmatic nuclei. Neuroreport 5, 2683-2687. doi: 10.1097/00001756-199412000-00069 
Lewy, A. J., Bauer, V. K., Ahmed, S., Thomas, K. H., Cutler, N. L., Singer, C. M., et al. (1998). The human phase response curve (PRC) to melatonin is about 12 hours out of phase with the PRC to light. Chronobiol. Int. 15, 71-83. doi: 10. 3109/07420529808998671

Lupi, D., Sekaran, S., Jones, S. L., Hankins, M. W., and Foster, R. G. (2006). Lightevoked FOS induction within the suprachiasmatic nuclei (SCN) of melanopsin knockout (Opn4-/-) mice: a developmental study. Chronobiol. Int. 23, 167-179. doi: 10.1080/07420520500545870

Mirmiran, M., and Kok, J. H. (1991). Circadian rhythms in early human development. Early Hum. Dev. 26, 121-128. doi: 10.1016/0378-3782(91)90016-v

Munekawa, K., Tamada, Y., Iijima, N., Hayashi, S., Ishihara, A., Inoue, K., et al. (2000). Development of astroglial elements in the suprachiasmatic nucleus of the rat: with special reference to the involvement of the optic nerve. Exp. Neurol. 166, 44-51. doi: 10.1006/exnr.2000.7490

Muñoz Llamosas, M., Huerta, J. J., Cernuda-Cernuda, R., and García-Fernández, J. M. (2000). Ontogeny of a photic response in the retina and suprachiasmatic nucleus in the mouse. Brain Res. Dev. Brain Res. 120, 1-6. doi: 10.1016/s01653806(99)00175-3

Nováková, M., Sládek, M., and Sumová, A. (2010). Exposure of pregnant rats to restricted feeding schedule synchronizes the SCN clocks of their fetuses under constant light but not under a light-dark regime. J. Biol. Rhythms 25, 350-360. doi: 10.1177/0748730410377967

Ohta, H., Honma, S., Abe, H., and Honma, K. (2002). Effects of nursing mothers on rPer1 and rPer2 circadian expressions in the neonatal rat suprachiasmatic nuclei vary with developmental stage. Eur. J. Neurosci. 15, 1953-1960. doi: 10. 1046/j.1460-9568.2002.02016.x

Ohta, H., Honma, S., Abe, H., and Honma, K. (2003). Periodic absence of nursing mothers phase-shifts circadian rhythms of clock genes in the suprachiasmatic nucleus of rat pups. Eur. J. Neurosci. 17, 1628-1634. doi: 10.1046/j.1460-9568. 2003.02584.x

Ohta, H., Xu, S., Moriya, T., Iigo, M., Watanabe, T., Nakahata, N., et al. (2008). Maternal feeding controls fetal biological clock. PLoS One 3:e2601. doi: 10. 1371/journal.pone.0002601

Okamura, H., Fukui, K., Koyama, E., Tsutou, H. L., Tsutou, T., Terubayashi, H., et al. (1983). Time of vasopressin neuron origin in the mouse hypothalamus: examination by combined technique of immunocytochemistry and [3H] thymidine autoradiography. Brain Res. 285, 223-226. doi: 10.1016/01653806(83)90055-x

Reppert, S. M., and Schwartz, W. J. (1983). Maternal coordination of the fetal biological clock in utero. Science 220, 969-971. doi: 10.1126/science.6844923

Reppert, S. M., and Schwartz, W. J. (1984). Functional activity of the suprachiasmatic nuclei in the fetal primate. Neurosci. Lett. 46, 145-149. doi: 10.1016/03043940(84)90432-4

Reppert, S. M., and Schwartz, W. J. (1986). Maternal suprachiasmatic nuclei are necessary for maternal coordination of the developing circadian system. J. Neurosci. 6, 2724-2729.

Reppert, S. M., Weaver, D. R., Rivkees, S. A., and Stopa, E. G. (1988). Putative melatonin receptors in a human biological clock. Science 242, 78-81. doi: 10. $1126 /$ science. 2845576

Romero, M. T., and Silver, R. (1990). Time course of peptidergic expression in fetal suprachiasmatic nucleus transplanted into adult hamster. Brain Res. Dev. Brain Res. 57, 1-6. doi: 10.1016/0165-3806(90)90177-z

Ruggiero, L., Allen, C. N., Brown, R. L., and Robinson, D. W. (2009). The development of melanopsin-containing retinal ganglion cells in mice with early retinal degeneration. Eur. J. Neurosci. 29, 359-367. doi: 10.1111/j.1460-9568. 2008.06589.x

Ruggiero, L., Allen, C. N., Brown, R. L., and Robinson, D. W. (2010). Mice with early retinal degeneration show differences in neuropeptide expression in the suprachiasmatic nucleus. Behav. Brain Funct. 6:36. doi: 10.1186/1744-9081-6-36

Schurov, I. L., Hepworth, T. J., and Hastings, M. H. (2002). Dopaminergic signalling in the rodent neonatal suprachiasmatic nucleus identifies a role for protein kinase A and mitogen-activated protein kinase in circadian entrainment. Eur. J. Neurosci. 15, 223-232. doi: 10.1046/j.0953-816x.2001.01848.x

Sekaran, S., Lupi, D., Jones, S. L., Sheely, C. J., Hattar, S., Yau, K. W., et al. (2005). Melanopsin-dependent photoreception provides earliest light detection in the mammalian retina. Curr. Biol. 15, 1099-1107. doi: 10.1016/j.cub.2005.05.053

Shibata, S., and Moore, R. Y. (1987). Development of neuronal activity in the rat suprachiasmatic nucleus. Brain Res. 431, 311-315. doi: 10.1016/01653806(87)90220-3
Shibata, S., and Moore, R. Y. (1988). Development of a fetal circadian rhythm after disruption of the maternal circadian system. Brain Res. 469, 313-317. doi: 10. 1016/0165-3806(88)90194-0

Shimada, M., and Nakamura, T. (1973). Time of neuron origin in mouse hypothalamic nuclei. Exp. Neurol. 41, 163-173. doi: 10.1016/0014-4886(73)90187-8

Shimomura, H., Moriya, T., Sudo, M., Wakamatsu, H., Akiyama, M., Miyake, Y., et al. (2001). Differential daily expression of Perl and Per2 mRNA in the suprachiasmatic nucleus of fetal and early postnatal mice. Eur. J. Neurosci. 13, 687-693. doi: 10.1046/j.0953-816x.2000.01438.x

Silver, R., Lehman, M. N., Gibson, M., Gladstone, W. R., and Bittman, E. L. (1990). Dispersed cell suspensions of fetal SCN restore circadian rhythmicity in SCN-lesioned adult hamsters. Brain Res. 525, 45-58. doi: 10.1016/00068993(90)91319-c

Sládek, M., Sumová, A., Kováciková, Z., Bendová, Z., Laurinová, K., and Illnerová, H. (2004). Insight into molecular core clock mechanism of embryonic and early postnatal rat suprachiasmatic nucleus. Proc. Natl. Acad. Sci. U S A 101, 62316236. doi: 10.1073/pnas.0401149101

Speh, J. C., and Moore, R. Y. (1993). Retinohypothalamic tract development in the hamster and rat. Brain Res. Dev. Brain Res. 76, 171-181. doi: 10.1016/01653806(93)90205-o

Swaab, D. F., Hofman, M. A., and Honnebier, M. B. (1990). Development of vasopressin neurons in the human suprachiasmatic nucleus in relation to birth. Brain Res. Dev. Brain Res. 52, 289-293. doi: 10.1016/0165-3806(90)90247-v

Swaab, D. F., Zhou, J. N., Ehlhart, T., and Hofman, M. A. (1994). Development of vasoactive intestinal polypeptide neurons in the human suprachiasmatic nucleus in relation to birth and sex. Brain Res. Dev. Brain Res. 79, 249-259. doi: 10.1016/0165-3806(94)90129-5

Takahashi, K., and Deguchi, T. (1983). Entrainment of the circadian rhythms of blinded infant rats by nursing mothers. Physiol. Behav. 31, 373-378. doi: 10. 1016/0031-9384(83)90204-4

Tarttelin, E. E., Bellingham, J., Bibb, L. C., Foster, R. G., Hankins, M. W., GregoryEvans, K., et al. (2003). Expression of opsin genes early in ocular development of humans and mice. Exp. Eye Res. 76, 393-396. doi: 10.1016/s00144835(02)00300-7

Torres-Farfan, C., Rocco, V., Monsó, C., Valenzuela, F. J., Campino, C., Germain, A., et al. (2006). Maternal melatonin effects on clock gene expression in a nonhuman primate fetus. Endocrinology 147, 4618-4626. doi: 10.1210/en.20060628

Tu, D. C., Zhang, D., Demas, J., Slutsky, E. B., Provencio, I., Holy, T. E., et al. (2005). Physiologic diversity and development of intrinsically photosensitive retinal ganglion cells. Neuron 48, 987-999. doi: 10.1016/j.neuron.2005.09.031

VanDunk, C., Hunter, L. A., and Gray, P. A. (2011). Development, maturation and necessity of transcription factors in the mouse suprachiasmatic nucleus. $J$. Neurosci. 31, 6457-6467. doi: 10.1523/JNEUROSCI.5385-10.2011

Viswanathan, N., and Davis, F. C. (1997). Single prenatal injections of melatonin or the D1-dopamine receptor agonist SKF 38393 to pregnant hamsters sets the offsprings' circadian rhythms to phases 180 degrees apart. J. Comp. Physiol. A 180, 339-346. doi: 10.1007/s003590050053

Viswanathan, N., Weaver, D. R., Reppert, S. M., and Davis, F. C. (1994). Entrainment of the fetal hamster circadian pacemaker by prenatal injections of the dopamine agonist SKF 38393. J. Neurosci. 14, 5393-5398.

Vosko, A. M., Schroeder, A., Loh, D. H., and Colwell, C. S. (2007). Vasoactive intestinal peptide and the mammalian circadian system. Gen. Comp. Endocrinol. 152, 165-175. doi: 10.1016/j.ygcen.2007.04.018

Weaver, D. R., and Reppert, S. M. (1989). Periodic feeding of SCN-lesioned pregnant rats entrains the fetal biological clock. Brain Res. Dev. Brain Res. 46, 291-296. doi: 10.1016/0165-3806(89)90292-7

Weinert, D. (2005). Ontogenetic development of the mammalian circadian system. Chronobiol. Int. 22, 179-205. doi: 10.1081/cbi-200053473

Wreschnig, D., Dolatshad, H., and Davis, F. C. (2014). Embryonic development of circadian oscillations in the mouse hypothalamus. J. Biol. Rhythms 29, 299-310. doi: $10.1177 / 0748730414545086$

Wurtman, R. J., Axelrod, J., and Fischer, J. E. (1964). Melatonin synthesis in the pineal gland: effect of light mediated by the sympathetic nervous system. Science 143, 1328-1329. doi: 10.1126/science.143.3612.1328

Yoo, S. H., Yamazaki, S., Lowrey, P. L., Shimomura, K., Ko, C. H., Buhr, E. D., et al. (2004). PERIOD2::LUCIFERASE real-time reporting of circadian dynamics reveals persistent circadian oscillations in mouse peripheral tissues. Proc. Natl. Acad. Sci. U S A 101, 5339-5346. doi: 10.1073/pnas.0308709101 
Yoshimura, T., Nishio, M., Goto, M., and Ebihara, S. (1994). Differences in circadian photosensitivity between retinally degenerate $\mathrm{CBA} / \mathrm{J}$ mice $(\mathrm{rd} / \mathrm{rd})$ and normal CBA/N mice (+/+). J. Biol. Rhythms 9, 51-60. doi: 10. $1177 / 074873049400900105$

Yujnovsky, I., Hirayama, J., Doi, M., Borrelli, E., and Sassone-Corsi, P. (2006). Signaling mediated by the dopamine D2 receptor potentiates circadian regulation by CLOCK:BMAL1. Proc. Natl. Acad. Sci. U S A 103, 6386-6391. doi: 10. 1073/pnas.0510691103

Conflict of Interest Statement: The authors declare that the research was conducted in the absence of any commercial or financial relationships that could be construed as a potential conflict of interest.
Received: 23 September 2014; accepted: 13 November 2014; published online: 01 December 2014.

Citation: Landgraf D, Koch CE and Oster H (2014) Embryonic development of circadian clocks in the mammalian suprachiasmatic nuclei. Front. Neuroanat. 8:143. doi: 10.3389/fnana.2014.00143

This article was submitted to the journal Frontiers in Neuroanatomy.

Copyright (c) 2014 Landgraf, Koch and Oster. This is an open-access article distributed under the terms of the Creative Commons Attribution License (CC BY). The use, distribution and reproduction in other forums is permitted, provided the original author(s) or licensor are credited and that the original publication in this journal is cited, in accordance with accepted academic practice. No use, distribution or reproduction is permitted which does not comply with these terms. 